\title{
O DIREITO HUMANO À ÁGUA POTÁVEL: INFLUÊNCIA DAS NORMAS DE SOFT LAW NO SEU PROCESSO DE AFIRMAÇÃO HISTÓRICA
}

\author{
THE HUMAN RIGHT TO DRINKING WATER: INFLUENCE OF SOFT LAW STANDARDS ON \\ ITS HISTORICAL AFFIRMATION PROCESS
}

\section{Pedro Gabriel Siqueira Gonçalves}

Mestrando em Direitos Humanos pela Universidade Federal de Mato Grosso do Sul - UFMS, Turma 2020/1. Mestre em Ciências Jurídicas pela Universidade Autônoma de Lisboa - UAL, com título reconhecido pela Universidade de Marília - UNIMAR. Procurador da República em Mato Grosso do Sul (MPF/MS). Procurador Regional dos Direitos do Cidadão - PRDC/MS, biênios 2017/2019 e 2019/2021. Procurador Regional Eleitoral - PRE/MS, biênio 2019/2021. Membro do Grupo de Pesquisa "Direitos Humanos, Meio Ambiente e Desenvolvimento Sustentável Global" (CNPq), Campo Grande - MS.

E-mail: pedro_gabriel@ufms.br

\section{Lívia Gaigher Bósio Campello}

Pós-Doutora em Direito do Estado pela Universidade de São Paulo (USP). Doutora em Direito das Relações Econômicas e Internacionais pela Pontifícia Universidade Católica de São Paulo (PUC/SP), Mestra em Políticas Públicas e Processo pelo Centro Universitário Fluminense (UNIFLU). Bacharela em Direito pela Universidade Vila Velha (UVV). Professora adjunta da Faculdade de Direito na Universidade Federal de Mato Grosso do Sul (UFMS).

Coordenadora do Programa de Mestrado em Direitos Humanos da UFMS. Coordenadora do Projeto de Pesquisa

"Mecanismos de Cooperação Internacional em matéria ambiental: aplicabilidade e relevância para o estado do Mato Grosso do Sul" (FUNDECT/MS), Campo Grande - MS. Líder do Grupo de Pesquisa "Direitos Humanos, Meio Ambiente e Desenvolvimento Sustentável Global" (CNPq), Campo Grande - MS. Editora-chefe da Revista de Direito UFMS, Campo Grande - MS. E-mail: liviagaigher@gmail.com

RESUMO: O reconhecimento de todo direito humano é marcado por historicidade e contextualizado por reivindicação social. Não foi diferente com o direito à água potável. A crise hídrica mundial, a desigualdade e discriminação no acesso à água despertou interesse na proteção da água sob o marco dos direitos humanos. A oposição de grupos interessados na "mercantilização" da água potável obstruiu a celebração de instrumento convencional de caráter universal e com efeitos vinculantes sobre o direito à água potável. A evolução deste direito humano ocorreu de forma lenta e gradual. Poucos tratados de direitos humanos regulamentaram o acesso à água potável, o fazendo de forma genérica, lateral e setorizada a grupos vulneráveis. Coube às normas de soft law preencher o vazio normativo instalado diante da paralisa dos Estados que endossavam concepções divergentes sobre o formato jurídico do direito à água potável. A flexibilidade e agilidade na aprovação das normas de soft law contribuíram para construção do regime jurídico do direito humano à água potável. A presente pesquisa demonstra que normas de soft law realizaram a catalisação da opinio juris dos Estados acerca da obrigatoriedade do direito humano à água potável, chancelando o comportamento (fatos materiais) que se pode notar a partir das ações 
concretas adotadas localmente para realização do direito, sugerindo o despertar de normas consuetudinárias. A partir do método de análise dedutivo conclui que a autonomia aos outros direitos humanos e a conceituação dos caracteres do direito humano à água potável são avanços inegáveis promovidos pelas normas de soft law.

Palavras-chave: Água potável. Direitos Humanos. Soft law.

ABSTRACT: The recognition of every human right is marked by historicity and contextualized by social demands. It was no different with right to drinking water. The global water crisis, inequality and discrimination in access to water has sparked interest in protecting water under the framework of human rights. The opposition of groups interested in the "commercialization" of drinking water obstructed the celebration of a conventional instrument of universal character and with binding effects on the right to drinking water. The evolution of this human right occurred slowly and gradually. Few human rights treaties have regulated access to drinking water, doing so in a generic, lateral and sectorized way to vulnerable groups. It was up to the soft law norms to fill the normative vacuum installed in the face of the paralysis of States that endorsed divergent conceptions about the legal format of the right to drinking water. The flexibility and agility in the approval of the soft law norms contributed to construction of the legal regime of human right to drinking water. This research demonstrates that soft law norms have catalyzed the opinion of the States regarding the mandatory human right to drinking water, supporting the behavior (material facts) that can be seen from the concrete actions adopted locally to realize the law, suggesting the awakening of customary norms. Based on the deductive analysis method, he concludes that autonomy from other human rights and the conceptualization of human right to drinking water are undeniable advances promoted by soft law rules.

Keywords: Drinking water. Human rights. Soft law.

SUMÁRIO: Introdução. $1 \mathrm{O}$ processo de afirmação histórica do direito humano à água potável. 2 O direito à água potável no marco jurídico dos direitos humanos: a primazia de normas de soft law e a verificação de avanços no sistema de proteção internacional. Conclusão. Referências.

\section{INTRODUÇÃO}

A preocupação mundial com a degradação do meio ambiente ganha tons peculiares quando dirige sua atenção ao debate sobre a água potável. Dada a essencialidade desse recurso natural para as atividades humanas, a água potável foi objeto de lutas e disputas em várias passagens da história, justamente porque o controle sobre a água sempre esteve ligado à ideia de poder. Quem controlasse a água expressaria o exercício de seu poder. No entanto, a crise hídrica mundial e as desigualdades no acesso à água potável despertaram interesse na discussão do tema sob o marco dos direitos humanos.

O presente artigo procura analisar o processo de afirmação histórica do direito humano à água potável no plano internacional. Notadamente, propõe-se a responder dois problemas centrais: i) quais razões justificaram a precedência das normas de soft law em relação às normas de hard law no desenvolvimento do regime jurídico do direito à água potável sob o marco dos direitos humanos? e, passo seguinte, ii) é possível identificar avanços no sistema internacional de proteção ao direito humano à água potável a partir das normas de soft law?

Para tanto, o desenvolvimento será articulado em duas seções. A primeira delas objetiva examinar o contexto e as perspectivas em que o tema "água potável" foi desenvolvido normativamente pelo direito internacional. Serão analisados três períodos em que a água potável foi objeto de regulamentação pelo direito internacional: água como "via de transporte", água como 
"bem ambiental" e água como "direito humano". O enredo de lutas e a historicidade do direito humano à água potável serão postos em evidência.

A segunda seção, a seu turno, realiza o recorte temático para aprofundar o exame das normas de soft law aprovadas no sistema global de proteção aos direitos humanos, analisando sua influência na construção do regime jurídico do direito à água potável sob o marco dos direitos humanos. Apurar-se-á propriamente as razões da primazia das normas de soft law e se houve avanços no sistema global de proteção ao direito humano à água potável.

Para atingir os objetivos propostos, será utilizada a pesquisa exploratória e descritiva, bibliográfica e documental com uma análise por meio de obras, artigos, declarações, convenções internacionais. O método de abordagem será o dedutivo, partindo de conceitos genéricos até sua particularização.

\section{O PROCESSO DE AFIRMAÇÃO HISTÓRICA DO DIREITO HUMANO À ÁGUA POTÁVEL}

O reconhecimento de qualquer direito humano enreda histórico de luta ou reivindicação social. A água potável, por sua vez, não foge a essa regra. A disputa pela água potável encerra relações de poder em todas as fases normativas em que o tema foi disciplinado pelo direito internacional, como se verá adiante. $\mathrm{O}$ reconhecimento e desenvolvimento do emergente direito humano à água potável também pode ser expressado pela dinamogenesis dos valores, no sentido de explicar o processo que fundamenta o nascimento e desenvolvimento de novos direitos no decorrer da história (SILVEIRA; ROCASOLANO, 2010, p. 185).

A essencialidade desse elemento natural (água física) para a realização dos principais objetivos da existência humana põe em evidência, na contemporaneidade, a necessidade de sua proteção jurídica no marco dos direitos humanos e no quadro da crescente degradação ambiental, esta particularmente conhecida na temática como crise hídrica. $\mathrm{O}$ surgimento de novos direitos humanos, em função de recentes demandas sociais da atualidade, retrata a ideia de inexauribilidade dos direitos humanos (RAMOS, 2017, p. 60).

Acerca da historicidade dos direitos humanos, Bobbio (2004, p. 18) aponta que "o elenco dos direitos do homem se modificou, e continua a se modificar, com a mudança das condições históricas, ou seja, dos carecimentos e dos interesses, das classes no poder, dos meios disponíveis para a realização dos mesmos, das transformações técnicas e etc.”.

A história de lutas pelo acesso à água pode ser dividida, a partir da perspectiva em que se valora o bem "água", em três momentos normativos bem definidos: i) o período da água como "via de transporte" para o comércio internacional e como "potencial energético" para a produção de energia; ii) o período da água como "bem ambiental" importante ao equilíbrio dos ecossistemas e regulação do clima e iii) o período da água como "direito humano", com acesso universal e não discriminatório, contrapondo-se à ideia de água como "mercadoria".

No primeiro período da tutela jurídica da água - água como "via de transporte" para o comércio internacional - a água era vista apenas como "um meio" de se promover a circulação de mercadorias pelo comércio internacional, mais uma via para o tráfego do comércio internacional. Nesse cenário, ganha destaque a regulamentação para o uso dos rios transfronteiriços internacionais, ao disciplinar não apenas o direito de passagem pelos rios internacionais como também a responsabilidade dos Estados fronteiriços. Aliás, pela preponderância da temática dos rios internacionais, esse ramo do direito internacional ficou conhecido como direito internacional fluvial (AMORIM, 2015, p. 94-97).

Além de via para o transporte de mercadorias, a água potável era concebida nesse período como "potencial armazenado" para a produção de energia. A disciplina jurídica desse primeiro período cuidou também de regulamentar o interesse dos Estados fronteiriços acerca do potencial hidroenergético representado pelos rios internacionais. A Convenção Relativa ao Desenvolvimento 
da Força Hidráulica que afete a Mais de um Estado, de 1923, adotada no âmbito da Sociedade das Nações, foi o ato multilateral, fugindo à regra dos acordos bilaterais, a tratar do tema nesse período (AMORIM, 2015, p. 98-100).

Característicos desse período da água como "via de transporte" foram os tratados bilaterais celebrados entre os Estados cujos territórios eram banhados pelos rios internacionais. São mencionados os seguintes como representantes do período: o Tratado de Versalhes de 1919, o Estatuto de Barcelona de 1921 e a Convenção de Paris sobre o Estatuto do Danúbio de 1921, os quais projetaram a noção liberal da navegação comercial, mediante a utilização ampla do trânsito fluvial de cargas e passageiras(os) por rios classificados como de interesse internacional (AMORIM, 2015, p. 96).

O segundo período da proteção jurídica da água potável - água como "bem ambiental" - é contemporâneo à evolução do direito internacional ambiental, no qual houve o despertar da consciência da comunidade internacional acerca da importância de se proteger o meio ambiente como "um bem em si", destacando a água como bem ambiental e seu papel na manutenção do processo hidrológico, do clima e etc.

A mudança de paradigma acerca do meio ambiente, sem dúvidas, foi promovida pela Declaração de Estocolmo de 1972. A Declaração de Estocolmo inaugura o processo de proteção internacional do meio ambiente, sendo que sua Declaração de Princípios já carrega a "preocupação de se adotar um regime jurídico para a água doce, que visasse ao acesso e à gestão humanista desse recurso vital, [...] (AMORIM, 2015, p. 108). A Declaração de Estocolmo trata do tema água potável sob a perspectiva de bem ambiental e suas funções ecológicas.

A Conferência de Estocolmo de 1972 iniciou a campanha mundial pela preservação da biosfera (COMPARATO, 2019, p. 426). Ela impulsionou o debate mundial sobre o meio ambiente e desenvolvimento, ensejando a realização de outras conferências globais sob o patrocínio da ONU, com destaque para: a Conferência sobre o Meio Ambiente e o Desenvolvimento de 1992, conhecida como Eco-92 (realizada no Rio de Janeiro), a Cúpula Mundial sobre o Desenvolvimento Sustentável de 2002 (ocorrida em Joanesburgo) e a Conferência sobre o Desenvolvimento Sustentável de 2012, conhecida como Rio+20 (realizada também no Rio de Janeiro).

$\mathrm{Na}$ visão de Comparato (2019, p. 426), as Convenções aprovadas no âmbito da Conferência Rio 92 (Convenção sobre a Biodiversidade Biológica e a Convenção-Quadro sobre Mudança do Clima) procuraram aplicar na esfera planetária o princípio fundamental da solidariedade, na perspectiva presente como futura; ou seja, "solidariedade entre todas as nações, povos e grupos humanos da mesma geração, bem como solidariedade entre a geração atual e as futuras.".

Entretanto, a compreensão de solidariedade não se esgota no dever moral de coexistência do grupamento humano. A solidariedade ingressa no campo jurídico e detém força imperativa para orientar a atividade dos Estados na proteção dos direitos humanos, como no caso do emergente direito à água potável. Para Sarlet e Fensterseifer (2017, p. 96), "há que transpor a noção de solidariedade para o plano jurídico-normativo, na condição de pilar fundamental para a construção de uma sociedade e de um Estado de Direito que tenham na guarda, proteção e promoção dos direitos fundamentais a sua maior missão.".

A ideia de solidariedade está presente desde a origem das discussões sobre o reconhecimento da água potável como direito humano. Desde tema como a preservação das bacias hidrográficas até o, da distribuição equitativa dos recursos hídricos, a solidariedade tem orientado os fóruns internacionais sobre o regime jurídico do direito à água potável. Ela provoca a abertura dos Estados à cooperação internacional, sobretudo mediante o compartilhamento de tecnologias no uso eficiente do recurso hídrico.

Nesse período da água como "bem ambiental”, a disciplina jurídica sobre o acesso à água potável aparece de forma prematura e lateral às discussões centrais sobre a temática do meio 
ambiente, enfocadas que estavam, à época, repita-se, na necessidade de se proteger o meio ambiente contra ações antropogênicas degradantes.

Significativos desse período são os seguintes instrumentos do direito internacional ambiental: Convenção sobre Zonas Úmidas de Importância Internacional (Convenção de Ramsar, 02/02/1971) $)^{1}$; Declaração de Estocolmo de $1972^{2}$, Convenção sobre a Proteção e Uso Transfronteiriço de Cursos d'Água e Lagos Internacionais ${ }^{3}$; Convenção Internacional sobre Combate à Desertificação nos Países Afetados por Seca Grave e/ou Desertificação de 1992 ${ }^{4}$; Convenção das Nações Unidas sobre Usos de Cursos D’Água Internacionais para fins Outros que a Navegação de $1997^{5}$; Convenção de Estocolmo sobre Poluentes Orgânicos Persistentes (POP) de 22/05/20016; Conferência Internacional da Água (Bonn, Alemanha, 2001) ${ }^{7}$; Convenção de Minamata sobre Mercúrio de 10/10/2013 ${ }^{8}$.

Com efeito, surgiu nesse quadro de proteção do meio ambiente e da água como "bem ambiental" a preocupação com a denominada crise hídrica mundial. A crise hídrica mundial, a título de ilustração, pode ser expressada pelos dados colhidos do relatório "Água e Saneamento: evidências para políticas públicas com enfoque em direitos humanos e resultados na saúde pública”, elaborado em 2011 pela Organização Pan-americana de Saúde - Opas, retratando que cerca de 40 milhões de pessoas na América Latina, ou seja, 7\% da população, não possuem água segura para o consumo humano. Além disso, aproximadamente 117 milhões de pessoas (cerca de $20 \%$ da população) não têm acesso a instalações sanitárias em condições mínimas de higiene. Dentro desse universo de carência de saneamento básico, 36 milhões de pessoas (mais de 6\% da população da região) ainda praticam a defecação ao ar livre, com graves consequências sociais e ambientais (OPAS, 2011, p. 10-11).

A crise hídrica mundial e as desigualdades no acesso à água potável e ao saneamento compõem o contexto no qual as lutas pelo reconhecimento da água potável sob "o marco dos direitos humanos" são travadas frente às tentativas de setores do comércio internacional de se postular a "mercantilização" da água potável, isto é, a tentativa de se enquadrar a água potável no conceito de mercadoria, sujeitando-a à regulamentação jurídica idêntica a qualquer outro bem que circula no mercado capitalista.

O “mercado das águas”, como é conhecido o processo de mercantilização da água potável, vem se desenvolvendo na contemporaneidade, alimentado pela crise hídrica mundial e pela implementação de novas tecnologias para a captação e transporte de grande volume de água a granel, in natura. Esse cenário de escassez e má distribuição dos recursos hídricos despertou o interesse econômico de grandes corporações multinacionais que se especializaram em todo o processo do "mercado das águas", desde a aquisição de direitos de propriedade sobre as reservas hidrológicas, permitindo-lhes a exploração comercial, até o beneficiamento e distribuição da água potável além fronteiras (AMORIM, 2015, p. 202-203).

\footnotetext{
1 Disciplinou a proteção das zonas úmidas como reservatório da biodiversidade e como reguladoras dos regimes hidrológicos.

2 Marco que representou mudança de paradigma no direito internacional em relação aos recursos naturais, contrapondo-se à visão estritamente econômica de apropriação dos elementos naturais e devastação do meio ambiente, apresentando preocupação com o esgotamento da biosfera por ação antrópica. O Princípio 2 da Declaração de Estocolmo coloca a água entre os bens objeto de tutela ambiental: “os recursos naturais da terra, incluindo o ar, a água, terra, flora e fauna e especialmente amostras representativas dos ecossistemas naturais devem ser preservados para o benefício das presentes e futuras gerações, através de planejamento e gestão apropriados e cuidadosos."

3 Conhecida como Convenção de Helsinki, adotada em 1992. Seu escopo foi adotar o princípio do poluidor-pagador, em relação à poluição das águas doces, instando os Estados a adotarem medidas legais e administrativas de gestão hidrológica.

4 O principal objetivo foi determinar a cooperação de países desenvolvidos a providenciar recursos financeiros aos países em desenvolvimento que sofrem com seca ou desertificação a adotarem planos nacionais de combate e prevenção e esses fenômenos.

5 O seu art. 5. ${ }^{\circ}$ prescreve que os Estados devem "utilizar os cursos d'água internacionais de modo equânime e razoável".

6 Veda a utilização e a produção de tais poluentes pelos Estados-partes, em função de sua alta periculosidade ao meio ambiente e à saúde humana, e reconhece a contaminação das águas por tais poluentes.

7 Realizada entre os dias 03 e 07.12.2001 recebeu o título "Água: chave para o desenvolvimento sustentável". Na ocasião foram apontados três aspectos para ação: governança - devendo contar com a participação de todos na tomada de decisão em relação aos recursos hídricos; recursos financeiros - incluindo o capital privado, implicando o princípio do poluidor-pagador e usuário-pagador; e capacidade de construir conhecimento compartilhado - na forma de educação ambiental, coleta de dados e disponibilização de informações, instituições mais efetivas, conhecimentos compartilhados e tecnologias inovadoras. (OLIVEIRA, 2015, p. 9)

8 Visa proteger a saúde humana e o meio ambiente contra as emissões antropogênicas de mercúrio e seus compostos.
} 
O caso do Chile exemplifica o efeito do "mercado das águas" na perspectiva de exclusão social, a ponto de convulsionar a sociedade civil contra os abusos tarifários praticados pelas empresas que exploram a comercialização da água potável naquele país, com efeitos severos sobre a população de baixa renda (AMORIM, 2015, p. 176).

A situação da Turquia que vende água potável para outros países do Oriente Médio revela que o "mercado das águas" tem a propensão de ingressar na agenda política do comércio exterior de Estados com grandes bacias hidrográficas e não apenas das empresas multinacionais (AMORIM, 2015, p. 201).

A situação de Israel e a postura de exploração desigual de bacias hidrográficas da vizinha Palestina, promovendo exclusão hídrica ao povo árabe, acrescenta mais um ingrediente ao conhecido conflito entre aqueles povos e desperta constantemente preocupação da comunidade internacional na garantia da paz e segurança (BULTO, 2015, p. 40).

Neste ponto, merece breve aprofundamento, pelo escopo do trabalho, a disputa pelo controle das bacias hídricas da região da Cisjordânia, encetada por Israel e o povo palestino. Essa situação, como veremos, estampa a face mais perversa do "mercado das águas", porque o uso da força militar e do poderio econômico por Israel reproduz o quadro de miséria e impede o desenvolvimento do povo palestino.

O povo palestino vê-se privado de acessar boa parte dos recursos hídricos de seu território desde a ocupação israelense após a Guerra dos Seis Dias em 1967. Acredita-se que o principal objetivo da ocupação israelense fora consolidar o domínio sobre a bacia hídrica, superficial e profunda, da Cisjordânia ${ }^{9}$, cujo controle atingiu aproximadamente $50 \%$ dos recursos hídricos após a guerra (ABU-BAKER, 2017, p. 38-39).

Israel utilizou-se de expedientes militares ${ }^{\mathbf{1 0}}$ e de poder diplomático para celebração de acordos bilaterias assimétricos ${ }^{\mathbf{1 1}}$ para o uso da água, consolidando a exploração hegemônica e discriminatória dos recuros hídricos do território palestino, dificultando sobremaneira o desenvolvimento de atividades econômicas que dependem do acesso à água pelas(os) palestinas(os) (ABU-BAKER, 2017, p. 39-40).

Esse quadro de privação aos recursos hídricos tem limitado o desenvolvimento econômico das(os) palestinas(os) que vivem no território palestino ocupado - TPO, dificultando a produção de alimentos, sedentação de animais e etc. A empresa israelense "Mekorot", responsável pela gestão dos recursos hídricos e distribuição da água doce na região, adotou regime tarifário que comprometeu boa parte do rendimento das famílias palestinas do TPO, agravando o quadro de probreza na região (ABU-BAKER, 2017, p. 43).

O quadro de pobreza das(os) palestinas(os), agravado pela escassez hídrica, potencializa os conhecidos e graves conflitos na região da Cisjordânia. Para Abud-Baker, a relação entre acesso à água e autodeterminação do povo palestino pode ser resumida nos seguintes termos: "a integração do sistema de água palestino ao de Israel e seu controle quase total sobre os recursos hídricos palestinos refletem as políticas de Israel destinadas a despojar os palestinos de suas riquezas naturais e, portanto, impede o direito do povo palestino à autodeterminação." (2017, p. 44).

A discussão sobre o tema "água potável”, no contexto global contemporâneo, é protagonizada por atores ligados às agências de proteção aos direitos humanos sob os auspícios da Organização das Nações Unidas - $\mathrm{ONU}^{12}$ e por agências ligadas ao comércio internacional de

\footnotetext{
9 Integrada pelo Rio Jordão, que corre ao leste da fronteira da Cisjordânia; o Aquífero da Montanha, subjacente à Cisjordânia e Israel; e o Aquífero Costeiro, subjacente à Faixa de Gaza e Israel.

10 Israel introduziu, logo após a guerra dos Seis Dias, mudanças legislativas sob a formatação de ordens militares, as quais declararam propriedade estatal todos os recursos hídricos da região e subordinavam todos os atos de gestão de recursos hídricos sob a autoridade de militares israelenses, notadamente permissões para manutenção ou reconstrução de infraestruturas hídricas.

11 Os Acordos de Oslo II legitimaram a exploração desigual dos recursos hídricos do Aquífero da Montanha à razão de $87 \%$ para Israel e $13 \%$ para os palestinos.

12 O principal evento mundial que congrega os debates políticos internacionais sobre a água potável e direitos humanos é o Fórum Mundial da Água, realizado pelo Conselho Mundial da Água e que já registra sua oitava edição, realizada em Brasília, Brasil, entre os dias 18 a 23 de março de 2018. A agenda política em favor da água potável como direito humano também é expressa pelos Objetivos de Desenvolvimento do Milênio (ODM 7) e pela atual Agenda 2030 para o Desenvolvimento Sustentável da ONU (ODS 6).
} 
mercadorias, com destaque para o Banco Mundial ${ }^{13}$ e sua política de investimentos que legitima o processo de mercantilização da água potável.

Enfim, o terceiro período de proteção jurídica da água potável, designado de água como "direito humano", é enredado pelas disputas entre aqueles que defendem o marco jurídico dos direitos humanos como forma de proteger a pessoa humana contra os efeitos perversos, discriminatórios e excludentes da agenda econômica do capitalismo na sua vertente neoliberal, que postula novas frentes de lucro com a mercantilização da água potável.

$\mathrm{Na}$ realidade, o marco jurídico dos direitos humanos visa estabelecer diretrizes para garantir o acesso à água potável segura e a preços módicos, evitando a ocorrência de abusos por parte dos detentores do direito de propriedade sobre a água, os quais podem estabelecer quadro tarifário no qual a(o) cidadã(o) é compelida(o) a realizar escolhas difíceis entre o abastecimento de água potável ou a satisfação de outros direitos tão caros à dignidade humana como a alimentação, saúde e moradia.

A seguir, ver-se-á como se desenvolveu propriamente o conteúdo jurídico do direito à água potável sob o marco dos direitos humanos.

\section{O DIREITO À ÁGUA POTÁVEL NO MARCO JURÍDICO DOS DIREITOS HUMANOS: A PRIMAZIA DE NORMAS DE SOFT LAW E A VERIFICAÇÃO DE AVANÇOS NO SISTEMA DE PROTEÇÃO INTERNACIONAL}

Como visto, o terceiro período de proteção da água potável, sob o marco jurídico dos direitos humanos, é enredado por intensas disputas entre aquelas(es) que postulam o reconhecimento da água como bem de uso comum, cujo acesso deve ser universalizado e não discriminatório, e aqueloutras(os) que vislumbram a água potável como mais um bem suscetível à apropriação privada, cuja exploração econômica renderia novas frentes de lucro ao capitalismo.

Esse embate de perspectivas sobre a roupagem jurídica do direito à água potável repercutiu decididamente no processo de construção do seu regime jurídico no plano internacional. A corrente oposicionista ao marco dos direitos humanos inviabilizou a construção de consensos sobre o direito humano à água potável, prejudicando a celebração de instrumento multilateral, com efeitos vinculantes, e com abrangência universal sobre o tema.

Vale dizer que, até os dias atuais, não há registro de um só tratado ou convenção, celebrados no plano global, que discipline, de forma específica, abrangente e com força vinculante, o tema do direito à água potável e suas múltiplas dimensões (conteúdo, características, obrigações e etc).

Revisitando as normas jurídicas que foram adotadas no plano internacional sobre a temática, percebe-se que pouquíssimas o foram sob o rótulo de hard law. O regime jurídico do direito humano à água potável foi construído preponderantemente a partir da soft law. Antes de avançarmos, contudo, apontaremos resumidamente o que entendemos por normas de hard e soft law.

A hard law está ligada à idéia de normas com força vinculante. Elas expressam o Direito tradicional, no qual o Estado exerce o monopólio da produção de normas jurídicas e cujas espécies normativas e respectivos ritos de aprovação são previamente previstos em instrumento formal. No Direito Internacional, as fontes da hard law são disciplinadas pelo artigo 38 do Estatuto da Corte Internacional de Justiça, designadamente os tratados, o costume e os princípios gerais de direito.

Por sua vez, a soft law é compreendida por Neves (2013, p. 263) como "um processo de produção de standards normativos, que têm como vocação a regulação de comportamentos sociais, sem caráter vinculativo e a cujo incumprimento não estão associadas sanções jurídicas.". A soft

13 Amorim refere que, em 1999, o Banco Mundial lançou sua política de investimentos sob o título "Tradeble Water Rigths - A Property Right Approach to Resolving Water Shortage and Promoting Investment", na qual endossa a perspectiva de que o regime de propriedade sobre a água reduziria o déficit causado pela gestão pública e evitaria a subcvalorização da água e o seu desperdício pelo consumidor (2015, p. 177).

Revista de Direito Brasileira | Florianópolis, SC | v. 28 | n. 11 | p.217-232 | Jan./Abr. 2021 
law está associada à ideia de flexibilidade, vinculatividade voluntária e perda do monopólio estatal na produção de normas.

Para Jean Salmon (apud NASSER, 2006, p. 25), as normas de soft law constituem "regras cujo valor normativo seria limitado, seja porque os instrumentos que as contêm não seriam juridicamente obrigatórios, seja porque as disposições em causa, ainda que figurando em um instrumento constringente, não criariam obrigações de direito positivo, ou não criariam senão obrigações pouco constringentes.".

Os comentários gerais expedidos por órgãos encarregados da interpretação de tratados internacionais são um bom exemplo de normas soft law para os interesses deste estudo.

Essas normas ou aparecem de forma pontual e episódica em importantes tratados do direito internacional humanitário, visando disciplinar o tratamento de prisioneiras(os) de guerra ${ }^{14}$ 15 ou garantindo o abastecimento da população civil ${ }^{16}$ e vítimas ${ }^{17}$ nos conflitos armados; ou aparecem de forma lateral em tratados de direitos humanos que regulamentam direitos de grupos vulneráveis específicos, como as mulheres ${ }^{18}{ }^{19}$, as crianças ${ }^{20} 21$ e as pessoas com deficiência ${ }^{22}$.

A forma setorizada, quase como exceção, como o tema do direito à água potável aparece nos tratados e convenções internacionais de direitos humanos revela a existência de impasses sobre o tema entre os Estados e, consequentemente, tem obstruído a construção do necessário consenso entre os atores globais para a celebração de instrumento específico, universal e conglobante sobre o tema do acesso à água potável.

Esse quadro genérico das normas de hard law possibilita o estabelecimento de relações assimétricas entre Estados soberanos em acordos bilaterais. Nesse sentido, acirra ainda mais as desigualdades entre os Estados na gestão dos recursos hídricos, favorecendo o Estado com maior poder econômico. Oliveira (2015, p. 12) assim sintetiza:

A falta de uma regulação universal sobre gestão dos recursos hídricos possibilita que os Estados soberanos firmem acordos bilaterais, a partir de seus interesses particulares, e nem sempre em condições igualitárias, podendo prevalecer às necessidades hídricas do país mais influente. Por este motivo é que advogamos no sentido de uma regulação internacional nos moldes de um grande tratado internacional de natureza hard law, fazendo com que metas sejam estabelecidas e sanções previstas para os Estados descumpridores, diante da grande importância que deve ser atribuído o direito ao acesso à água e ao saneamento para a vida de todas as pessoas.

O tema da água potável, e o seu reconhecimento como direito humano, foi objeto da mais acessa e intensa controvérsia entre os direitos de matriz socioeconômica. "De fato, talvez nenhum

\footnotetext{
14 A Convenção de Genebra Relativa ao Tratamento dos Prisioneiros de Guerra (Genebra III) de 1949 estabelece obrigação de fornecimento de água potável aos prisioneiros de guerra (arts. 20, 26, 29 e 46).

15 O Protocolo Adicional II, de 1977, às Convenções de Genebra de 1949, estabelece a obrigação de fornecimento de água potável aos prisioneiros e proíbe ataque, destruição ou remoção de instalações relativas ao abastecimento de água e irrigação à população (arts. 5. e 14, respectivamente). 16 A Convenção de Genebra Relativa à Proteção de Civis em tempo de Guerra (Genebra IV) de 1949 estabelece a obrigação de fornecimento de água potável aos civis detidos, contidos ou acantonados para consumo, necessidades pessoais e higiene (arts. 85, 89 e 127).

17 O Protocolo Adicional I, de 1977, às Convenções de Genebra de 1949, sobre a Proteção das Vítimas de Conflitos Armados estabelece a proibição de destruição de instalações, reservas de água potável e obras de irrigação (art. 54).

18 A Convenção para a Eliminação de Todas as Formas de Discriminação contra as Mulheres de 1979 estabelece a obrigação aos Estados-Partes de assegurar às mulheres que vivem na zona rural o direito de gozar de condições adequadas de vida, notadamente serviços de saneamento e de abastecimento de água (art. 14). É tão específica que acaba excluindo as mulheres da zona urbana.

19 O Protocolo à Carta Africana dos Direitos dos Homens e dos Povos, Relativo aos Direitos da Mulher na África, de 2003, estabelece o direito das mulheres a uma alimentação sadia e adequada e à água potável (art. 15).

20 A Convenção das Nações Unidas sobre os Direitos das Crianças de 1989 estabelece aos Estados-Partes a obrigação de combater doenças e má nutrição, devendo adotar medidas apropriadas para tal objetivo, com o fornecimento de alimentos nutritivos e de água potável (art. 24).

21 A Carta Africana dos Direitos e Bem-Estar das Crianças de 1990 subordina o direito fundamental de acesso à água potável à realização do direito à saúde (art. 14 (2) (c)).

22 Convenção das Nações Unidas sobre as Pessoas com Deficiência de 2006 prescreve o direito das pessoas com deficiência a um padrão adequado de vida, implicando a obrigação de os Estados-Partes garantir o acesso à água potável e ao saneamento.
} 
outro direito no catálogo internacional de direitos socioeconômicos tenha tido seu status e sua base normativa tão contestada como o direito humano à água." (BULTO, 2015, p. 40).

A obstrução da via de hard law abriu passagem para a adoção de outros instrumentos mais flexíveis, menos formais, menos burocráticos, sujeitos a quórum menos rigoroso de aprovação, designadamente a via das normas de soft law. Reis e Campello destacam como um dos fatos positivos para utilização das normas de soft law justamente a menor burocracia e maior velocidade para sua elaboração e negociação (2018, p. 89).

O processo de gestação do regime jurídico do direito humano à água potável foi lento e gradual, a exemplo do que ocorreu com o contemporâneo processo de afirmação do direito internacional ambiental. Ambos foram intensificados no final da década de 60 do século XX (SARLET; FENSTERSEIFER, 2017, p. 44).

A primeira referência acerca do tema direito humano à água potável nas normas de soft law é apontada na Conferência de Mar Del Plata, entre 14 e 25 de março de 1977. A conferência foi organizada sob os auspícios da ONU e resultou em consenso de que caberia a cada Estado soberano a promoção de políticas públicas de acesso à água de boa qualidade e saneamento básico para a totalidade da população até 1990.

Esse compromisso da Conferência de Mar del Plata foi o embrião de ações globais posteriores com a finalidade de pautar ações políticas locais dos Estados na promoção da universalização do acesso à água e ao saneamento, tais como as Décadas de Ações pela Água, o Objetivo do Milênio 7 e o contemporâneo Objetivo de Desenvolvimento Sustentável 6 da Agenda 2030 da ONU.

Após a Conferência de Mar Del Plata de 1977, houve a adoção de sucessivos instrumentos de soft law reiterando a necessidade de os Estados reconhecerem (e, via de consequência, respeitarem e garantirem) o direito humano à água potável. Entretanto, a construção do regime jurídico do direito humano à água potável pelas normas de soft law não ocorreu de forma linear e progressiva com o acréscimo de elementos entre um ato e outro.

Nesse caminho, nota-se ora a adoção de atos com conteúdo genérico - sobrelevando apenas a afirmação do direito humano -, ora de atos que efetivamente contribuem para construção do seu conteúdo jurídico, a exemplo da qualidade, quantidade suficiente, preço acessível, responsabilidade primária do Estado, e etc., como se verá adiante.

Na perspetiva de apenas afirmar o direito humano à água potável e a necessidade de acesso universal, sem aprofundar seu conteúdo, citam-se como representativos das normas de soft law os seguintes instrumentos adotados no âmbito da ONU: Conferência Internacional sobre Água e Desenvolvimento Sustentável (Paris, 1998) ${ }^{23}$, Resolução 54/175 da Assembleia Geral da ONU, de 15/02/2000 24 , Conferência Mundial para o Desenvolvimento Sustentável (Johannesburgo, África do Sul, 2002) ${ }^{25}$, Resolução A/HRC/RES/18 ${ }^{26}$ e a Declaração Final da Conferência Rio+20, de $2012^{27}$.

Além dos instrumentos globais, aponta-se, na mesma linha de abordagem genérica, uma resolução adotada no âmbito do sistema regional americano de proteção aos direitos humanos. Trata-se da Resolução AG/doc.5242/12 ver.2 da Assembleia Geral da Organização dos Estados Americanos - OEA, adotada em 04/06/2012, que reconheceu que o acesso à água potável e ao saneamento contribui para o combate à pobreza.

23 Foi realizada no âmbito da Unesco, entre os dias 19 e 21.03.1998. Os países participantes, levando em consideração a situação concreta de cada um deles, comprometeram-se a: (a) fomentar a integração de todos os aspectos do aproveitamento, a gestão e a proteção dos recursos hídricos com a elaboração de planos destinados a satisfazer as necessidades essenciais e promover uma distribuição eficiente e equitativa dos recursos hídricos, a proteção dos ecossistemas e a preservação do ciclo hidrológico.”(OLIVEIRA, 2015, p. 9)

24 Esta resolução estabelece em seu artigo 12 que a plena realização do direito ao desenvolvimento como direito humano depende do reconhecimento do direito humano de acesso à água e comida.

25 Ocorrida entre 26/08 e 04/09/2002, ela reforçou as metas do milênio, seguindo o objetivo anteriormente planejado, ou seja, reduzir pela metade, até 2015, a população sem acesso à água e ao saneamento básico. (OLIVEIRA, 2015, p. 9)

26 Em 28/09/2011, o Conselho de Direitos Humanos da ONU aprovou a A/HRC/RES/18 conclamando os Estados a garantir o financiamento necessário para o fornecimento sustentável dos serviços de água e saneamento.

27 Reafirmou o compromisso dos Estados signatários com o reconhecimento do direito humano de acesso à água potável e ao saneamento. Revista de Direito Brasileira | Florianópolis, SC | v. 28 | n. 11 | p.217-232 | Jan./Abr. 2021 
De outro lado, representativos das normas de soft law que agregaram conteúdo ao regime jurídico do direito humano à água potável, citam-se os seguintes instrumentos: Carta de Montreal sobre Água Potável e Saneamento de 20/06/199028, Agenda 21, Capítulo $18^{29}$, Conferência Internacional sobre Água e Meio Ambiente, de 26 a 31 de janeiro de 1992 (Conferência de Dublin) ${ }^{30}$, Comentário Geral n. ${ }^{\text {o }} 15$ do Comitê de Direitos Econômicos, Sociais e Culturais da ONU, Resolução 64/292 de 28/07/2010 ${ }^{31}$ e Resolução A/HRC/15/L.14 de setembro de $2010 .{ }^{32}$

Todos esses últimos instrumentos, a seu tempo e contexto nos quais foram adotados, contribuíram para ampliar o conteúdo jurídico do direito humano à água potável, ora reconhecendo a necessidade de se agregar dados quantitativos/qualitativos ao fornecimento de água, ora enfatizando a modicidade das tarifas de acesso à água, ora encarecendo a responsabilidade primária dos Estados pela satisfação desse direito ainda quando o serviço seja delegado a terceiros.

Todavia, dois deles merecem destacada atenção pela forma como sedimentaram avanços no regime jurídico do direito humano à água potável. O Comentário Geral n. ${ }^{\circ} 15$ do Comitê de Direitos Econômicos, Socais e Culturais sintetizou as principais características do direito humano à água potável e ao saneamento. E a Resolução da Assembleia Geral da ONU n. ${ }^{\circ}$ 64/292, de 28/07/2010, que reconheceu expressa e formalmente a existência do direito humano à água potável, sacramentando sua independência, autonomia em relação aos demais direitos humanos.

Com efeito, o Comentário Geral $n .^{\circ} 15$ trouxe balizas a orientar a forma como o direito humano à água potável deve ser respeitado, protegido, promovido pelos Estados. O Comitê de Direitos Econômicos, Sociais e Culturais procedeu à interpretação dos artigos 11 e 12 do Pacto Internacional de Direitos Econômicos Sociais e Culturais - PIDESC de 1966 para expressar a existência do direito humano à água potável e apontar suas principais características.

Em relação ao artigo $11, \S 1 .^{\text {o }},{ }^{33}$ do Pacto Internacional de Direitos Econômicos, Sociais e Culturais, o Comitê procedeu à interpretação teleológica do dispositivo, procurando extrair o direito humano à água da referência normativa explícita sobre o direito a um padrão de vida adequado. O Comitê apontou a partícula incluindo que precede a lista de itens que compõem o direito ao padrão de vida adequado (alimentação, vestuário e moradia) como indicativo de que se trataria de rol não taxativo, possibilitando a inclusão da água na lista de direitos protegidos, porque está em consonância com o objeto e o propósito do artigo 11, § 1. ${ }^{\circ}$ (BULTO, 2015, p. 33-34).

Já em relação ao artigo $12, \S 1 .^{034}$, o Comitê procedeu à abordagem derivativa, no sentido de extrair o direito humano à água a partir da previsão de outros direitos humanos intimamente relacionados, designadamente a saúde física e mental. "O CESCR afirmou que o direito humano à água deveria ser visto em conjunção com as garantias do Artigo 12, § 1o, do ICESCRs notadamente o direito ao mais alto padrão possível de saúde, os direitos à moradia e alimentação adequadas, (...)". (BULTO, 2015, p. 33-34).

O Comentário Geral n. ${ }^{\circ} 15$ apontou a existência de opinio juris dos Estados sobre o direito humano à água potável ao enumerar os principais documentos, tratados e outros instrumentos

28 O seu preâmbulo prevê "o acesso à água potável é uma condição de sobrevivência" e, por isso, o direito de acesso à água potável, em quantidade e qualidade suficientes para a satisfação de suas necessidades básicas, é indissociável de outros direitos da pessoa humana.

29 O seu principal objetivo em relação à água doce é a de "satisfazer as necessidades de água doce de todos os países para o seu desenvolvimento". 18.2 "A água é necessária em todos os aspectos da vida. O objetivo geral é assegurar que se mantenha uma oferta adequada de água de boa qualidade para toda a população do planeta, ao mesmo tempo em que se preservem as funções hidrológicas, biológicas e químicas dos ecossistemas, adaptando as atividades humanas aos limites da capacidade da natureza".

30 Realizada em Dublin, Irlanda, resultando na Declaração de Dublin sobre Água e Desenvolvimento Sustentável, estabelecendo os chamados Princípios de Dublin, cujo princípio 4 estabelece ser "vital o reconhecimento em primeiro lugar o direito elementar de todos os seres humanos de ter acesso à água potável e saneamento a um preço que todos tenham disponibilidade financeira para pagar (affordable price).”

31 A Assembleia Geral da ONU aprova a Resolução 64/292 e reconhece oficialmente que "o direito à água potável e ao saneamento é um direito humano fundamental, essencial ao pleno gozo da vida e de todos os direitos humanos". ONU expressa a necessidade de reconhecimento explícito e autônomo do direito à água potável, não ficando restrito ao reconhecimento da conexão com outros direitos fundamentais.

32 Em setembro de 2010, o Conselho de Direitos Humanos da ONU aprovou a Resolução A/HRC/15/L.14 que reconhece o direito humano de acesso à água potável e ao saneamento, reafirmando que os Estados têm a responsabilidade primária de garantir a realização desse direito humano, cuja delegação de seu fornecimento a terceiros não os exonera desta responsabilidade.

33 Os Estados-Parte do presente acordo reconhecem o direito de todos a um padrão de vida adequado para si e sua família, incluindo alimentação, vestuário e moradia adequados, e à melhoria contínua das condições de vida. Os Estados-Parte realizarão os passos apropriados para assegurar a realização deste direito, reconhecendo para isto a importância crucial da cooperação internacional baseada em livre consentimento.

34 Os Estados-Parte no presente acordo reconhecem o direito de todos de usufruir o mais alto padrão possível de saúde física e mental.

Revista de Direito Brasileira | Florianópolis, SC | v. 28 | n. 11 | p.217-232 | Jan./Abr. 2021 
internacionais que reconheceram expressamente o direito humano à água potável (item 4. do instrumento). Ele apontou, de forma inédita, três vetores que orientam a configuração do conteúdo jurídico do direito humano à água potável, quais sejam: a) disponibilidade; b) qualidade e c) acessibilidade e suas quatro dimensões.

Por disponibilidade, o Comentário Geral prescreve que o fornecimento de água potável deve ser contínuo e suficiente para o uso pessoal e doméstico, os quais devem ser entendidos como o uso para beber, preparo de alimentos, higiene pessoal, limpeza doméstica, lavagem de roupas. A quantidade suficiente de água dever ser aquela apontada pelas diretrizes da Organização Mundial da Saúde. Alguns indivíduos e grupos, dadas condições de saúde, clima e trabalho, podem demandar quantidade adicional de água para os mesmos fins (item 12.a).

Por qualidade, o Comentário Geral regulamenta que a água disponível deve ser segura, livre de contaminação por micro-organismos, substâncias químicas ou perigos radiológicos que representam perigo para a saúde da pessoa (item 12.b).

Por acessibilidade, o Comentário Geral disciplina que as instalações e os serviços de fornecimento de água devem estar acessíveis a todos sem discriminação dentro do território do Estado. Dada a alta carga semântica do vetor acessibilidade, o Comentário Geral subdividiu-o em quatro dimensões para facilitar a compreensão do conteúdo, limites e possibilidades de cada um deles.

Como indicado acima, a acessibilidade comporta quatro dimensões sobrepostas: a) acessibilidade física, entendida como o dever de os serviços de fornecimento de água estarem ao alcance físico e seguro de todos os setores da população; b) acessibilidade econômica, significando que os custos diretos e indiretos do acesso à água devem ser acessíveis e não devem comprometer a realização de outros direitos econômicos e sociais; c) não-discriminação, os serviços de fornecimento de água devem abranger os grupos vulneráveis ou marginalizados da população, sem discriminação vedada e d) acessibilidade informacional, no sentido de buscar, obter e receber informações sobre a gestão da água. (itens 12. c; c.i, c.ii, c.iii e c.iv).

Além do conteúdo jurídico do direito à água potável, o Comentário Geral enfatiza os tradicionais deveres que competem aos Estados com relação aos direitos humanos, sob as perspectivas do respeito e garantia. Vale dizer, o Comentário Geral n. ${ }^{\circ} 15$ previu não só o direito em si, mas também garantias de proteção, notadamente pela previsão de responsabilidade internacional dos Estados diante do direito humano à água potável. A disciplina das obrigações de respeito e garantia consta nos itens 21 a 29 da referida norma de soft law. Veremos logo adiante.

Em relação às obrigações de respeito e garantia, elas traduzem o conteúdo jurídico da responsabilidade internacional dos Estados na proteção de direitos humanos. Os tratados e convenções internacionais de direitos humanos preveem as obrigações de respeito e garantia, ao lado dos direitos propriamente ditos, como forma de viabilizar a tutela jurídica dos direitos humanos no plano internacional. Tais obrigações apontam balizas para a responsabilização dos Estados no caso de violação.

A obrigação de respeito materializa-se num comportamento passivo do Estado, num não fazer. Ela traduz limitações ao Poder Público diante do direito humano. Na jurisprudência da Corte Interamericana de Direitos Humanos, o conceito de obrigação de respeito aos direitos humanos foi desenvolvido a partir do caso Velasquez Rodriguez. (Sentença de 29 de julho de 1988), no qual sedimentou o entendimento de que o dever de respeito têm caráter negativo, um dever de abstenção de condutas que resultem violação de direitos humanos (RAMOS, 2004, p. 41).

Já o dever de garantia é a contraface do de respeito. A garantia traduz a ideia de comportamento ativo do Estado em favor da realização do direito humano, impondo-lhes deveres de fazer. Ao Poder Público, compete agir e adotar medidas idôneas à promoção, em sentido amplo, do direito humano protegido. Ao Estado, não compete apenas a abstenção de comportamentos, potencial ou efetivamente, violadores de direitos humanos. 
Para André de Carvalho Ramos (2004, p. 41), o dever de garantia impõe aos Estados o estabelecimento de organização "de estruturas e procedimentos capazes de prevenir, investigar e mesmo punir toda violação, pública ou privada, dos direitos fundamentais da pessoa humana, mostrando a faceta objetiva desses mesmos direitos.".

Esses deveres, especificamente em relação ao direito humano à água, traduzem a necessidade de os Estados se absterem de interferir direta ou indiretamente no gozo do direito à água (respeitar, itens 21 e 22); impeçam que terceiros interfiram de alguma forma no gozo do direito à água (garantia, itens 23 e 24) e tomem medidas positivas para ajudar indivíduos a gozar do direito à água, promovam medidas educativas para estimular o uso racional da água e que forneçam a grupos que não sejam capazes de ter acesso a uma fonte de água por situações que fujam ao seu controle (garantia, itens 25 a 29).

A seu turno, a Resolução da Assembleia Geral da ONU n. ${ }^{\circ}$ 64/292, de 28/07/2010, contribuiu para o reconhecimento da autonomia do direito humano à água potável em relação aos demais direitos humanos, afastando-se da abordagem derivativa que via o direito à água potável como subordinado a outro direito humano, como a vida, a saúde e etc.

Esse reconhecimento do direito humano à água permite a postulação pela(o) respectiva(o) titular independente de violação a um suposto direito humano interligado. Afirma-se assim a violação ao direito à água potável, independentemente de essa violação representar também ameaça à vida ou saúde do titular.

A pessoa sofre violação ao direito à água potável ao não ter acesso a fontes seguras, ao residir distante da fonte de água, ao receber quantidades diárias inferiores ao consumo para atender as necessidades de higiene e alimentação. Essa violação pode ser verificada mesmo quando os seus efeitos sobre os direitos à saúde e vida sejam protraídos no tempo.

Vale dizer, o reconhecimento da autonomia do direito humano à água potável autoriza a postulação de tutela jurídica independente da verificação de violação a direitos humanos conexos e pretensamente superiores.

Por fim, importante inferir que as normas de soft law acabam por catalisar a opinio juris dos Estados acerca da obrigatoriedade do direito à água potável, no sentido do surgimento de um costume internacional quanto ao direito humano à água potável.

A partir do artigo 38 do Estatuto da Corte Internacional de Justiça, o costume internacional está em que ele constitua "uma prática geral aceita como direito", podendo ser detectado dois elementos principais na formação das normas consuetudinárias: os fatos materiais, isto é, o comportamento propriamente dito dos Estados e a opinio juris, consistente na crença psicológica ou subjetiva de que aquele comportamento é conforme a lei (SHAW, 2010, p. 59).

Note-se que os Estados têm assumido o compromisso de promover o direito humano à água potável nos principais fóruns globais, a exemplo das discussões que ocorrem no âmbito dos Fóruns Mundiais da Água, dos compromissos assumidos no âmbito dos Objetivos de Desenvolvimento do Milênio (ODM 7) e daqueles assumidos durante a construção dos Objetivos de Desenvolvimento Sustentável da Agenda 2030 (ODS 6). O cumprimento da meta do ODM 7 (acesso à água potável à metade da população mundial) simboliza que os Estados realizaram ações concretas (fatos materiais) para concretização do direito humano à água potável, ultrapassando claramente o espectro do mero debate político.

A recorrência do tema na agenda política para o desenvolvimento sustentável da ONU sinaliza que o direito humano à água potável encontra desafios a serem vencidos. O quadro de escassez hídrica e as desigualdades na distribuição da água potável, centrais no ODM 7, são confrontados com a necessidade de se garantir outras dimensões da água potável além da perspectiva quantitativa.

A água potável tem de ser segura (livre de contaminação e outros agentes patogênicos) e acessível (física, financeiramente e de forma não discriminatória) - características estas centrais ao atual ODS 06. 
O ODS 6, ou Sustainable Development Goal 6 (SDG 6) em Inglês, composto por 8 metas, que visam "Assegurar a disponibilidade e gestão sustentável da água e saneamento para todas e todos", trata de saneamento e recursos hídricos em uma perspectiva integrada. Permite avaliar o cenário de cada país quanto à disponibilidade de recursos hídricos, demandas e usos da água para as atividades humanas, ações de conservação dos ecossistemas aquáticos, redução de desperdícios e acesso ao abastecimento de água, esgotamento sanitário e tratamento dos esgotos (ANA, 2019, p. 07).

Houve um grande avanço dos ODS em relação aos ODM, no sentido de trazer a questão da água e do saneamento para o centro da discussão, tendo sido criado um objetivo exclusivo para tratar detalhadamente do tema, que passa a considerar uma visão mais abrangente da água como recurso hídrico, em termos de quantidade ou qualidade, enquanto era limitada anteriormente ao acesso aos serviços de saneamento: água e esgoto (ANA, 2019, p. 09).

Além disso, a aprovação da Resolução n. ${ }^{\circ}$ 64/292, de 28/07/2010, da Assembleia Geral da ONU, embora registrasse 29 ausências e 41 abstenções, contou com a votação expressiva de 122 Estados integrantes das Nações Unidas favoráveis ao reconhecimento explícito do direito humano à água potável e saneamento e sua independência em relação aos outros direitos humanos.

A maioria formada entorno da Resolução n. ${ }^{\circ}$ 64/292 expressa a opinio juris destes Estados quanto à obrigatoriedade do direito humano à água potável. Aqueles Estados que aquiesceram aos termos da resolução creem na juridicidade do direito humano à água potável. Sinaliza-se, portanto, o surgimento de um costume internacional sobre o tema.

A recorrência do tema água potável nas principais agendas políticas da ONU, Cúpula do Milênio e Agenda 2030, para o desenvolvimento sustentável, como visto, além de um desafio, não deixa de expressar o compromisso dos Estados com a satisfação deste direito humano. Ele é posicionado pelos Estados como elemento estratégico para a consecução de objetivos globais para o desenvolvimento sustentável, tais como o combate à fome e a erradicação da pobreza.

Enfim, enquanto não se celebra instrumento universal e obrigatório sobre o direito humano à água potável, as normas de soft law têm se incumbido da tarefa de coletar, a cada resolução, a cada declaração ou a cada outro documento aprovado sobre o tema, a aquiescência (opinio juris) dos Estados que creem na obrigatoriedade do emergente direito humano à água potável, contribuindo quiçá para a formação de normas consuetudinárias.

\section{CONCLUSÃO}

Como visto, o processo de reconhecimento do direito humano à água potável foi objeto de intensa controvérsia no direito internacional. $\mathrm{O}$ debate foi protagonizado entre os atores globais que reivindicaram o marco jurídico dos direitos humanos como forma de tutelar o direito à água potável e evitar a exclusão e discriminação contra aqueloutras(os) que defendiam a necessidade de "mercantilização" da água potável como forma de estimular seu uso racional e evitar o desperdício, promovendo a proteção do recurso natural.

O dissenso quanto a melhor fórmula de se proteger o direito à água potável obstruiu a celebração de instrumento multilateral, de caráter universal e com efeitos vinculantes, sobre o tema do direito humano à água potável. As poucas convenções internacionais que trataram da matéria inserem-na de forma lateral e setorizada, abrangendo grupos vulneráveis particularizados, tais como prisioneiras(os) de guerra, mulheres, crianças e pessoas com deficiência, como visto. Os poucos tratados bilaterais que trataram do tema têm dificuldade de estabelecer relações isonômicas em função da assimetria de poder subjacente aos Estados celebrantes.

A construção do regime jurídico de proteção internacional do direito humano à água potável ficou a cargo das normas de soft law. A flexibilidade de seus termos, carregados de expressões deliberadamente ambíguas, contribuíram para ampliar o rol de direitos tutelados pelo direito internacional dos direitos humanos, reconhecendo autonomia e independência ao direito à 
água potável (Resolução n. ${ }^{\circ}$ 64/292 da Assembleia Geral da ONU) e traçando suas principais características (Comentário Geral n. ${ }^{\circ} 15$ do CODESC).

A agilidade e não burocratização na aprovação das normas de soft law foram decisivas para desobstruir os canais vetustos de hard law e responder tempestivamente ao anseio global pelo reconhecimento jurídico (e não apenas político) do emergente direito humano à água potável.

Viu-se, também, que as normas de soft law atuaram como catalisadores da opinio juris dos Estados quantos aos principais caracteres do direito humano à água potável. A autonomia do direito frente aos demais direitos humanos e a construção de balizas para configuração do direito (disponibilidade, qualidade e acessibilidade) constituem inegáveis avanços das normas de soft law que contribuem para a efetiva postulação jurídica do direito humano à água potável.

$\mathrm{O}$ ingresso da maior parte dos Estados que compõem as Nações Unidas nos Fóruns Mundiais sobre a Água e nos compromissos das agendas políticas pela Água - seja no âmbito do predecessor ODM 7, seja no contemporâneo ODS 6 - e a posterior implementação interna de medidas concretas para a promoção do direito humano à água potável retratam a ocorrência de fatos materiais que dão substrato ao reconhecimento da opinio juris quanto à obrigatoriedade deste direito, possibilitando o surgimento quiçá de normas consuetudinárias.

Se é muito pensar no surgimento de costume internacional sobre o tema, não é pouca a contribuição das normas de soft law. Estas seguramente resgataram a autonomia do direito humano à água potável e construíram critérios que orientam sua efetiva proteção jurídica.

\section{REFERÊNCIAS}

ABU-BAKER, Aseil. Privados de Água. Sur - Revista Internacional de Direitos Humanos, v. 14, n. 25, p. 37-55, 2017.

AMORIN, João Alberto Alves. Direito das Águas. O regime jurídico da Água Doce no Direito Internacional e no Direito Brasileiro. São Paulo: Atlas, 2015.

AGÊNCIA NACIONAL DE ÁGUAS E SANEAMENTO BÁSICO - ANA. ODS 6 no Brasil: visão da ANA sobre os indicadores, 2019. Disponível em: <https://www.ana.gov.br/acesso-ainformacao/institucional/publicacoes/ods6/ods6.pdf>. Acesso em 17 fev. 2021.

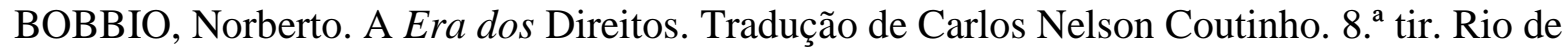
Janeiro: Elsevier, 2004.

BULTO, Takele Soboka. Muito familiar para ignorar, muito novo para reconhecer: a situação do direito humano à água potável em nível global. In: CASTRO, José Esteban; HELLER, Léo; MORAIS, Maria da Piedade (edit.). O Direito à água como política pública na América Latina: uma exploração teórica e empírica. Brasília: Ipes, 2015. cap. 1, 25-57.

CESCR - COMMITTEE ON ECONOMIC, SOCIAL AND CULTURAL RIGHTS. General Comment $n .^{\circ} 15$ : substantive issues arising in the implementation of the International Covenant on Economic, Social and Cultural Rights. Geneva: United Nations, 11-29 Nov. 2002.

COMPARATO, Fábio Konder. A afirmação histórica dos direitos humanos. 12. ${ }^{a}$ ed. São Paulo: Saraiva, 2019.

NASSER, Salem Hikmat. Fontes e Normas do Direito Internacional: um estudo sobre a Soft Law. 2. ${ }^{a}$ ed. São Paulo: Atlas, 2006. 
NEVES, Miguel Santos. Direito Internacional da Água e conflitualidade internacional: implicações do reconhecimento da água como direito humano. JURISMAT, Portimão, n. ${ }^{\circ}$ 3, p. 261-291, 2013.

OLIVEIRA, Celso Maran de; AMARANTE JUNIOR, Ozelito Possidônio de. Evolução das regras jurídicas internacionais aplicáveis aos recursos hídricos. Revista de Direito Ambiental, vol. 80/2015, p. 423-447, Nov. - Dez. 2015.

OPS - ORGANIZACIÓN PANAMERICANA DE LA SALUD. Agua y saneamiento: evidencias para políticas públicas con enfoque en derechos humanos y resultados en salud pública. Washington: OPS, 2011.

PIOVESAN, Flávia. Direitos Humanos e o Direito Constitucional Internacional. 11. a ed. rev. atual. São Paulo: Saraiva, 2010.

RAMOS, André de Carvalho. Curso de Direitos Humanos. 4. ed. São Paulo: Saraiva, 2017.

Responsabilidade Internacional por Violação de Direitos Humanos. Rio de Janeiro:

Renovar, 2004.

REIS, João Henrique Souza dos; CAMPELLO, Lívia Gaigher Bósio. Razões para a utilização de normas de soft law no Direito Internacional do Meio Ambiente. Revista Brasileira de Direito Internacional, Salvador, vol. 4, n. 1, p. 83-103, Jan. - Jun. 2018.

SARLET, Ingo Wolfgang; FENSTERSEIFER, Tiago. Direito Constitucional Ambiental: Constituição, Direitos Fundamentais e Proteção do Meio Ambiente. 5. ed. rev. São Paulo: Revista dos Tribunais, 2017.

. Princípios do Direito Ambiental. 2 ed. São Paulo: Saraiva, 2017.

SHAW, Malcolm N. Direito Internacional. Tradução de Marcelo Brandão Cipolla, Lenita Ananias do Nascimento, Antônio de Oliveira Sette-Câmara. Coordenação e revisão da tradução, Marcelo Brandão Cipolla. São Paulo: Martins Fontes, 2010.

SILVEIRA, Vladmir Oliveira da; ROCASOLANO, Maria Mendez. Direitos Humanos: conceitos, significados e funções. São Paulo: Saraiva, 2010.

SILVEIRA, Vladmir Oliveira da; PEREIRA, Taís Mariana Lima. Uma nova compreensão dos direitos humanos na contemporaneidade a partir dos objetivos de desenvolvimento sustentável (ODS). Revista Jurídica Cesumar, v. 18, n. 3, p. 909-931, Set. - Dez. 2018.

UN - NAÇÕES UNIDAS. Conferência sobre o Meio Ambiente Humano de 05 a 16 de junho de 1972. Estocolmo: UN, 1972. Disponível em:

<https://www.un.org/ga/search/view_doc.asp?symbol=A/CONF.48/14/REV.1>. Acesso em: 13 jun. 2020.

UN - NAÇÕES UNIDAS. Convenção Internacional sobre Combate à Desertificação nos Países Afetados por Seca Grave e/ou Desertificação de 1994. Nova Iorque: UN, 1994. Disponível em: 
$\langle$ https://www.mma.gov.br/estruturas/sedr_desertif/_arquivos/unccd_portugues.pdf $>$. Acesso em: 13 jun. 2020.

UN - UNITED NATIONS. International Covenant on Economic, Social and Cultural Rights (ICESCR). 16 Jan 1966.

UN - UNITED NATIONS. The human right to water and sanitation. Resolution A/RES/64/292. New York: UN, 2010. Disponível em: 〈http://goo.gl/Lu2wyD>.

UNECE - Comissão Econômica das Nações Unidas para a Europa. Convenção sobre a Proteção e Uso Transfronteiriço de Cursos d'Água e Lagos Internacionais de 1992 (Convenção de Helsinki). Helsinki: UNECE, 1992. Disponível em:

<https://www.unece.org/fileadmin/DAM/env/water/publications/WAT_Text/Convention_text_Po rtuguese.pdf $>$. Acesso em: 13 jun. 2020.

UNESCO - Organização das Nações Unidas para a Educação, Ciência e Cultura. Convenção sobre Zonas Úmidas de Importância Internacional de 02/02/1971. Ramsar: UNESCO, 1971. Disponível em:

<https://www.ramsar.org/sites/default/files/documents/library/scan_certified_e.pdf $>$. Acesso em: 13 jun. 2020. 